\title{
ENERGETIC PERFORMANCE ANALYSIS OF DRYING AGRICULTURAL PRODUCTS INTEGRATED WITH SOLAR TRACKING
}

\author{
I. O. Ohijeagbon ${ }^{1,}{ }^{*}$, L. I. Ogunfowora ${ }^{2}$, J. I. Omale ${ }^{3}$ and P. Ameh ${ }^{4}$ \\ 1,23,4DEPARTMENT OF MECHANICAL ENGINEERING, UNIVERSITY OF ILORIN, P.M.B. 1515, ILORIN, KWARA STATE NIGERIA \\ Email addresses:1idehaiohi@yahoo.com,2ogunfowora.lekan@gmail.com,3jio362@mail.usask.ca, \\ 4pamekoh@yahoo.com
}

\begin{abstract}
Renewable energy sources such as solar energy for drying purposes in a more effective and efficient way is inevitable for preservation of agricultural products in developing nations with inadequate access to electricity. This study investigates the effects of using a solar tracking device on the energy performance of drying processes. Three categories of drying conditions were carried out simultaneously; for a fixed solar box dryer, a solar box dryer aided by a tracking device, and open air drying over an effective total drying time of 6 hours each day, for 5 days. The average solar intensity for the open air, fixed and tracking collector drying were determined as 156.54, 180.72 and $186.81, \mathrm{~W} / \mathrm{m}^{2}$ corresponding to average drying temperatures of $32.17,43.31$ and $45.93{ }^{\circ} \mathrm{C}$ respectively. Solar intensity of open air drying can be increased by as much as 15.45-19.34\% if fixed and tracking solar collector systems are employed. Integration of a tracking device enhances the solar intensity of collectors during drying; which translates to accelerated drying process and drying efficiency.
\end{abstract}

Keywords: Solar energy; Agricultural products; Developing nations; Energy performance; Drying efficiency; Open air drying; Fixed collector drying; Tracking collector drying

\section{INTRODUCTION}

Modern technological advancement has led to the development of sophisticated means of drying, especially for various commercial and industrial applications and processes. While modern drying methods are highly valuable with regards to being able to maintain very good sanitary standards and optimum process control, however, continuous reliance on electricity is a significant and unavoidable cost in the use of modern dryers. Drying can be carried out either at high temperature, such as hot air drying or dielectric heating, or at low temperature, such as in refrigeration drying, or at ambient temperature, such as desiccant drying; in any case energy consumption is involved [1]. In view of the high demand of energy resources and nonsustainability of conventional energy sources, such as fossil fuels, it is imperative to continue to explore alternative methods of drying in a sustainable and more effective and efficient way, making use of renewable energy sources.

Drying is simply a process in which agricultural products can be preserved for future use by removing enough moisture from the crops in order to avoid decomposition, since moisture in many categories of agricultural produce makes them prone to perish more easily, especially in tropical climatic conditions [2-4]. Solar energy remains a viable and economical means of preservation of agricultural products, since the heat from solar energy can be applied in either traditional open air drying or with specially designed solar thermal dryers to prevent post harvest losses which are a common phenomenon in many developing countries [5-7]. In many part of the world where traditional open air drying is being practiced, the method is found to utilize solar energy inefficiently, and also highly susceptible to contamination from the environment resulting in poor quality of dried products [8].

Tremendous effort had been targeted at effectively exploiting solar thermal energy for drying various kinds of agricultural products. Such designs include; one layer of drying tray in which solar energy that falls on the dryer is trapped and directly warms the drying tray, such dryers have poor air flow and often fail to reach ideal drying temperatures on cloudy days. 
The many layers of drying trays allows the solar collector to increase the heat and air flow to the drying chamber, unfortunately, the many layers of trays reduces the airflow, which often leads to uneven drying and moldy food [9]. Mohsin et al. [10] studied the prospects and performance of various design of solar dryer for use in Bangladesh; these included the natural convection solar dryers and forced convection solar dryers. Mohsin et al. [10] observed that the drying air temperature can be achieved by simply adjusting collector length (in solar tunnel dryer) or air flow rate by changing the number of fans in operation. In an attempt to optimize solar energy drying processes, design of drying systems had been developed by various researchers for specific agricultural products and geographical locations, such as the development of solar drying model for selected Cambodian fish species, determining slice thickness of banana (Musa spp.) for enclosed solar drying using solar cabinet dryer under Ethiopian condition, simple solar drying system for banana fruit and solar dryer chamber used for convective drying of sponge-cotton in Egypt, grain size and heat source effect on the drying profile of cocoa beans in Nigeria, and solar drying shed for cassava in Malawi [11-16]. Most of the solar drying systems diversely in operation are usually fixed in a nominal position or optimum tiltangle inclination to the incident solar energy radiation. The major limitation of a fixed solar dryer system is the fact that it will lose a substantial amount of solar energy at certain periods of the day when the Sun movement have shifted from the optimum capture position. This obvious limitation is the reason why this study integrates solar tracking system into the solar energy drying process.

A solar tracking system is fundamentally employed to maximize energy extraction. This is very essential as it is expected to enhance performance and efficiency of solar energy systems which are widely used for domestic and industrial purposes, since the output power produced by solar thermal and photovoltaic systems is directly related to the amount of solar energy acquired by the system [17]. In the past, solar energy devices, such as solar panels where usually fixed in-between the geographical east and west with approximately 30 degrees towards the south in order to maximize energy extraction [18]. With advances in technology, solar tracking devices have been developed and applied to orient photovoltaic panels, reflectors, lenses or other optical devices toward the sun. This ensures that collection systems are adequately aligned with the Sun to maximize energy production, since the position of the Sun in the sky is constantly changing with the time of the day and the seasons of the year [19].

The majority of application of solar tracking systems is in the area of electrical energy generation from solar energy. Solar tracking system is hardly used for solar drying purposes. The purpose of this study is to investigate the effect of solar tracking on the energy performance of a solar box dryer in comparison with a fixed position solar box dryer and open air drying processes.

\section{THEORETICAL FRAMEWORK}

\subsection{Useful Energy Required for Drying A Unit Amount of A Crop}

The amount of water to be removed from crops $m_{r}$ ( $\mathrm{kg}$ ) can be calculated as [20-21]

$$
m_{r}=\frac{m_{i}\left(M_{f}-M_{i}\right)}{1-M_{i}}
$$

Where, $m_{i}$ is the initial mass of wet sample; while $M_{i}$ and $M_{f}$ are the initial fraction and final fraction of moisture contents. The moisture content on wet basis $\left(M_{i}\right)$ and on dry basis $\left(M_{f}\right)$ are given by [22-23]:

$$
\begin{aligned}
M_{i} & =\frac{m_{i}-m_{f}}{m_{i}} \\
M_{f} & =\frac{m_{i}-m_{f}}{m_{f}}
\end{aligned}
$$

$m_{f}$ is the dried or final mass of the sample over a time period.

The useful energy $(k J)$ required for drying a unit amount of a crop on dry mass basis can be determined by [20]:

$$
\begin{array}{r}
E_{\text {useful }}=m_{i}\left[\left(\frac{1-M_{f}}{1-M_{i}}\right) \cdot C_{w}\left(T_{d}-T_{a}\right)\right. \\
\left.+\left(\frac{M_{i}-M_{f}}{1-M_{i}}\right) \cdot h_{f g}\right]
\end{array}
$$

The first term on the right-hand side of equation (4) represents the useful energy required for sensible heating of the wet crop from ambient temperature $T_{a}$ to drying temperature $T_{d}$; while the second term represents the useful energy required for the evaporation of moisture in the crop; and $h_{f g}$ representing the enthalpy of evaporation of water at the drying temperature. The specific heat $c_{w}$ (kJ/kg.K) of the wet sample can be estimated using a simple model of an unfrozen food [20,24] given by:

$$
C_{w}=4.19-2.30 x_{i}-0.628 x_{i}^{3}
$$

where, $x_{i}$ is the initial mass fraction of the solids in the food, given by: 


$$
x_{i}=1-M_{i}
$$

\subsection{Drying Efficiency}

Assuming that heat loss from the dryer medium to the ambient air is negligible and heat utilized to increase the temperature of the product and to evaporate moisture from the product, hence, the drying efficiency $\eta_{d}(\%)$, at any time period is expressed as [25]:

$$
\eta_{d}=\frac{\left(m_{r} \times L+m_{f} \times C_{w} \times \Delta T\right)}{A \times I_{t} \times t}
$$

Here, the latent heat of vaporization $L(J / \mathrm{kg})$ was determined at the drying air temperature $T_{d}\left({ }^{0} K\right)$ according to ASAE as [25]:

$L=2,502,535.259-2,385.76424\left(T_{d}-273.16\right)$

In (7) and (8), 273.16 $\leq T_{d} \leq 338.72, t$ is the desired time period (3600 sec); $A$ is surface area of the drying space $\left(m^{2}\right) ; m_{r}$ is water evaporated during a time period ( $k g$ ), as stated by equation (1); $m_{f}$ is mass of sample at a time period $(\mathrm{kg})$, as stated in equations (2) and (3); $C_{w}$ is specific heat of samples, as stated by equations (4) and (5); $\Delta T$ is the temperature difference between air temperature inside the drying compartment and ambient air temperature $\left({ }^{0} \mathrm{~K}\right)$; $I_{t}$; is total solar intensity on horizontal surface $\left(W / \mathrm{m}^{2}\right)$. Assuming the earth and collector to act as a black body system, then the total solar intensity of a normal black radiation consequence of the Stefan-Boltzmann law and Lambert's law may be expressed as [26-27]:

$$
I_{t}=\frac{\sigma T^{4}}{\pi}
$$

In (9), $I_{t}$ is the total solar intensity $\left(\mathrm{W} / \mathrm{m}^{2}\right), \sigma$ is the Stefan-Boltzmann constant $=56.7 \times \frac{10^{-12} \mathrm{~kW}}{\mathrm{~m}^{2} \mathrm{~K}^{4}}$ and $T$ is the Temperature of emitting surface $\left({ }^{0} \mathrm{~K}\right)$. The temperatures of tracking and fixed collectors and open air drying were used to estimate the temperature of emitting surface.

\section{MATERIALS AND METHOD}

\subsection{Equipments and Apparatus}

\subsubsection{Solar Tracking Device}

This is a device which helps to orientate a solar photovoltaic panel or concentrating solar reflector or lens or solar box dryer in the case of present study toward the sun. It is most useful in varying the angle of solar panels and collectors to take advantage of the full amount of the sun's energy. This is done by rotating the collector or box dryer in a direction perpendicular to the Sun's angle of incidence. The solar tracker used in this study is a single-axis tracker that simply rotates about one axis, azimuthally moving from east to west over the course of the day. Generally the design of the solar tracker consists of four major components, namely, the supporting structure, electrical control, drive system and the collector support. The need for the tracker was to provide a dynamic tracking of the sun to provide effective collection of the solar radiation for effective drying.

\subsubsection{Solar Box Dryer or Collector}

The solar box dryer used in this study was designed to be suitable for household drying of agricultural products. The Box dryer has a collector area of 0.1702 $\mathrm{m}^{2}$ and the dimension given as: length, ' $46 \mathrm{~cm}$ ', width, '37 cm', and height, '20 cm'. The dryer can conveniently dry about $4 \mathrm{~kg}$ of agricultural products in a single batch. The dryer design was based on thermal performance and product quality optimization. A $3 \mathrm{~mm}$ thick glass was used as cover glazing. The top of the dryer was made in such a manner that the glass can be inserted and removed at the top of the box for cleaning when needed by sliding the glass into the space provided. This facilitates opening and closing of the cover glass, allowing access inside the box for loading and unloading the products spread on the tray. The dryer operated in natural draft principle. The dryer has a wooden tray kept inside the box for loading the products to be dried. The tray was partitioned into three compartments to enable different product to be dried simultaneously.

\subsubsection{Weighing Balance}

A weighing balance was used for measuring samples of dried agricultural products. This enabled the determination of the difference in the weight of the crops before and after the drying process in order to calculate the moisture loss during the drying period.

\subsubsection{Thermometer}

The purpose of the thermometer was to take the temperature of the drying chamber of solar box collector as well as the ambient temperature. This helps to ascertain the temperature used for drying of the products. Basically the range of thermometer used in this study varies from $0^{\circ} \mathrm{C}$ to $110^{\circ} \mathrm{C}$. This was to enable a wide range of temperatures reading.

\subsection{Experimental Procedure}

The experimental set-up was carried out on two solar box dryers. Three categories of drying conditions 
were carried out simultaneously for various agricultural products. The first condition of drying was carried out in a solar box dryer fixed at a tilt angle of approximately $10^{\circ}$ latitude facing south to maximize the incident solar radiation for the domain of the experiment. The second condition of drying was carried out by placing another solar box dryer similar to the first one on the tracking device in order to capture the effective real-time optimum solar energy possible. The third condition of drying which serves as the control was the open air drying. Ambient and drying temperatures and initial and final masses were obtained for samples of dried agricultural products under the three drying conditions described earlier over an effective total drying time of 6 hours each day, for 5 days. The daily averages of measured data of dried groundnuts are presented in table 1.

\section{RESULTS AND DISCUSSION}

\subsection{Analysis of Temperatures with Open Air Drying, Fixed and Tracking Collectors}

The ambient temperatures, $T_{a}$ presented in table 1 were the measured minimum daily temperatures.
Table 1 indicates a maximum average daily ambient temperature on the third day, that is, at a total drying time of 18 hours, which resulted in an average drying temperature, $T_{d}$ of $45.57{ }^{0} C$ and $49.00{ }^{0} C$ in the fixed and tracking collectors respectively. The nonlinearization of the drying temperature changes with ambient temperatures observed in table 1 could be as a result of other environmental factors such as air speed, cloud cover and humidity respectively.

\subsection{Solar Intensity for Drying}

The solar intensity for drying groundnuts was lowest for the open air drying and highest for the tracking collector drying as shown in Figure 1. This clearly indicates that higher drying temperatures were realised with the aid of the fixed and tracking collectors. The average solar intensity for the open air, fixed and tracking collector drying were obtained as $156.54,180.72$ and $186.81 \mathrm{~W} / \mathrm{m}^{2}$, corresponding to average drying temperatures of 32.17, 43.31 and $45.93{ }^{0} \mathrm{C}$ for the open air, fixed and tracking collector drying respectively.

Table 1: Mass of dried samples of groundnuts under different drying conditions

\begin{tabular}{|c|c|c|c|c|c|c|c|c|c|c|c|}
\hline \multirow{4}{*}{ Days } & \multirow{4}{*}{$\begin{array}{l}\text { Total } \\
\text { drying } \\
\text { time } \\
\text { (hours) }\end{array}$} & \multirow{4}{*}{$\begin{array}{l}\text { Ambient } \\
\text { temperature } \\
T_{a},\left({ }^{0} C\right)\end{array}$} & \multicolumn{3}{|c|}{$\begin{array}{l}\text { Average daily drying } \\
\text { temperatures, } T_{d}\left({ }^{0} C\right)\end{array}$} & \multicolumn{6}{|c|}{ Mass of dried groundnut samples (g) } \\
\hline & & & \multirow{3}{*}{$\begin{array}{c}\text { (Open } \\
\text { air) }\end{array}$} & \multicolumn{2}{|c|}{ Collector used } & $\begin{array}{c}\text { Initial } \\
\text { mass }\end{array}$ & $\begin{array}{l}\text { Final } \\
\text { mass }\end{array}$ & $\begin{array}{c}\text { Initial } \\
\text { mass }\end{array}$ & $\begin{array}{l}\text { Final } \\
\text { mass }\end{array}$ & $\begin{array}{c}\text { Initial } \\
\text { mass }\end{array}$ & $\begin{array}{l}\text { Final } \\
\text { mass }\end{array}$ \\
\hline & & & & \multirow[b]{2}{*}{ (Fixed) } & \multirow[b]{2}{*}{ (Tracking) } & \multirow{2}{*}{\multicolumn{2}{|c|}{ (Open air) }} & \multicolumn{4}{|c|}{ Collector used } \\
\hline & & & & & & & & \multicolumn{2}{|c|}{ (Fixed) } & \multicolumn{2}{|c|}{ (Tracking) } \\
\hline 1 & 6 & 28 & 33.71 & 42.57 & 44.21 & 87.5 & 85.0 & 82.5 & 77.5 & 60.0 & 50.0 \\
\hline 2 & 12 & 26 & 29.76 & 39.71 & 41.73 & 85.0 & 83.5 & 77.5 & 75.5 & 50.0 & 45.0 \\
\hline 3 & 18 & 29 & 33.17 & 45.57 & 49.00 & 83.5 & 74.5 & 75.5 & 64.5 & 45.0 & 30.0 \\
\hline 4 & 24 & 28 & 32.26 & 43.86 & 46.71 & 74.5 & 68.5 & 64.5 & 56.5 & 30.0 & 19.0 \\
\hline 5 & 30 & 28 & 31.93 & 44.86 & 48.00 & 68.5 & 64.5 & 56.5 & 52.5 & 19.0 & 13.0 \\
\hline
\end{tabular}

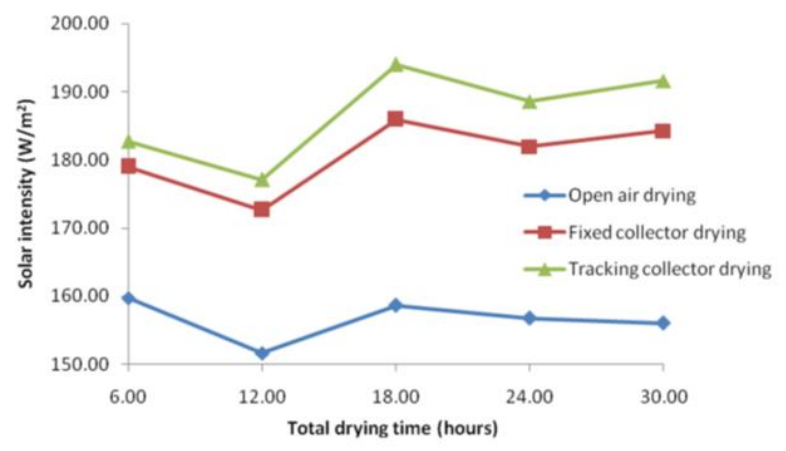

Figure 1: Variation of solar intensity with total drying time

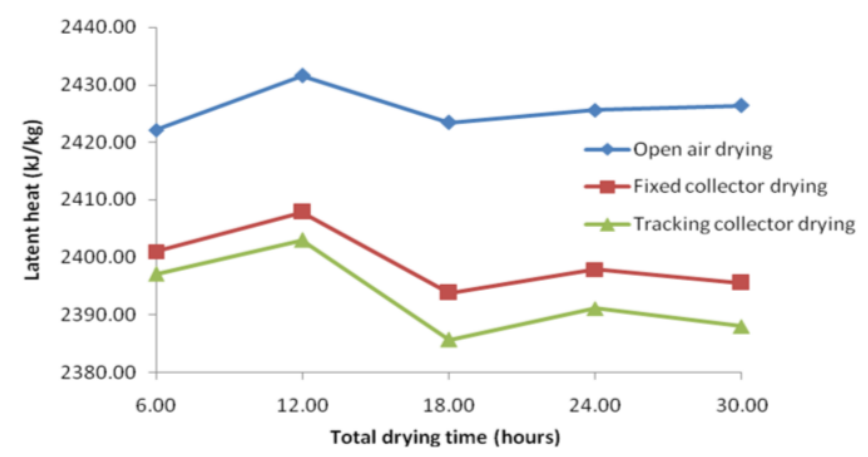

Figure 2: Variation of latent heat with total drying time 


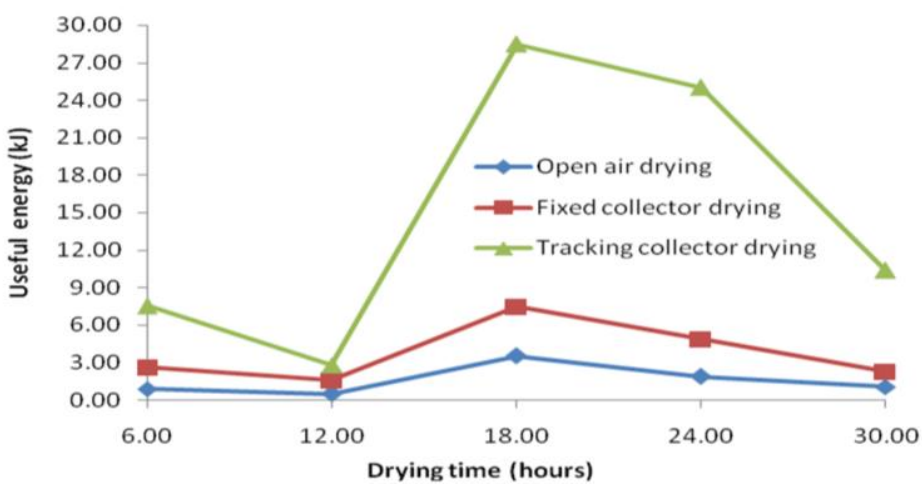

Figure 3: Variation of useful energy with total drying time

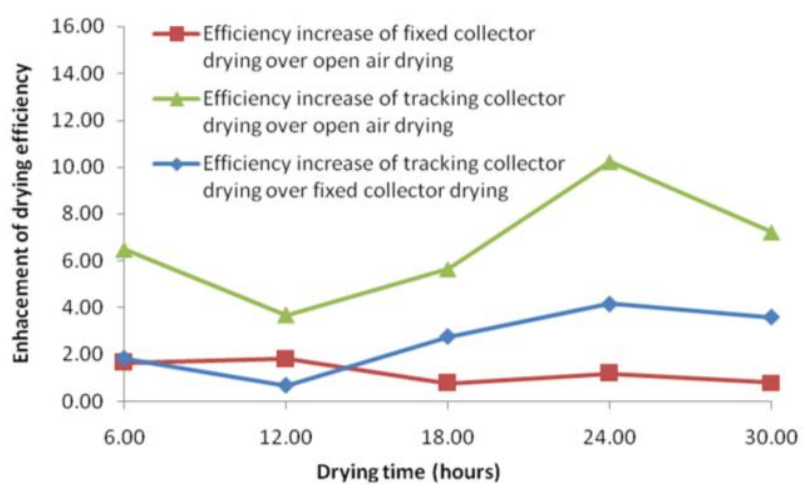

Figure 4: Variation of enhanced drying efficiency with total drying time

\subsection{Latent Heat for Drying}

The latent heat of vaporization for drying groundnuts was lowest for the tracking collector drying and highest for the open air drying as shown in figure 2 . This indicates that latent heat was inversely proportional to the solar drying intensity, and as such, higher latent heat is required for open air drying in contrast to those of solar collectors; which was characterised by lower drying temperature experienced in open air drying. The average latent heat of vaporization for the open air, fixed and tracking collector drying were obtained as 2425.79, 2399.20 and $2392.96 \mathrm{~kJ} / \mathrm{kg}$, corresponding to average drying temperatures of $32.17,43.31$ and $45.93{ }^{\circ} \mathrm{C}$ for the open air, fixed and tracking collector drying respectively.

\subsection{Useful Energy for Drying}

The average useful energy, mass of water removed and drying efficiency for the open air drying were obtained as $1.56 \mathrm{~kJ}, 0.43 \mathrm{~g}$ and $0.27 \%$; while those of fixed collector drying were obtained as $3.76 \mathrm{~kJ}, 0.84 \mathrm{~g}$ and $0.54 \%$; and those of tracking collector drying were obtained as $14.84 \mathrm{~kJ}, \quad 5.67 \mathrm{~g}$, and $2.11 \%$ respectively, corresponding to average drying temperatures of $32.17,43.31$ and $45.93{ }^{0} C$ for the open air, fixed and tracking collector drying respectively. The useful energy, mass of water removed and drying efficiency were all found to vary correspondingly to one another. The useful energy for drying groundnuts was lowest for the open air drying and highest for the tracking collector drying as shown in figure 3. Greater energy that could be utilised for drying was generated in the solar collectors in comparison with the open air drying. This resulted in increased rate of drying and drying efficiency respectively.

\subsection{Enhanced Drying Efficiency}

Results had shown that drying efficiency of agricultural products were greatly enhanced when solar collector dryers were used to dry agricultural products when compared with ordinary open air drying, with greater enhancement obtained in the case of the tracking collector. Figure 4 shows that higher enhanced drying efficiency was obtained with the tracking collector as compared with that of the fixed collector over open air drying. The figure 4 also shows that after some period of drying, higher enhanced efficiency may be achieved with the tracking collector drying over the fixed collector drying than in the case of fixed collector drying over the open air drying. The average enhanced efficiency factors were determined as 1.24, 2.60 and 6.65 for fixed collector over open air drying, tracking collector over fixed collector drying, and tracking over open air drying respectively.

\section{CONCLUSIONS}

Clean energy can be effectively generated and enhanced for drying agricultural and allied products with the use of solar collectors integrated with solar tracking devices. This will go a long way to saving the cost of conventional energy resources and mitigating the several problems and challenges, such as environmental pollution and degradation, and ozone layer depletion that often arise as a result of increasing demand and continuous use of conventional energy sources as fossil fuels. Solar intensity of open air drying can be increased by as much as $15.45-19.34 \%$ if fixed and tracking solar collector systems are employed. Increases in solar intensity of drying agricultural products would automatically translate to accelerated drying process and drying efficiency. Aside from the above mentioned benefits, agricultural products undergoing drying can be further prevented from unnecessary contaminations by microorganisms when exposed 
directly to the atmosphere through the use of enclosed solar box dryers.

\section{REFERENCES}

1. Bano, T., Goyal, N. and Tayal P. K. "Innovative Solar Dryers for Fruits, Vegetables, Herbs and Ayurvedic Medicines Drying", International Journal of Engineering Research and General Science, 3 (5), pp. 883-888, (2015).

2. Eze, J. I. and Agbo, K. E. "Comparative Studies of Sun and Solar Drying of Peeled and Unpeeled Ginger", American Journal of Scientific and Industrial Research, 2 (2), pp.136-143, (2011).

3. Wakjira, M. "Solar Drying of Fruits and Windows of Opportunities in Ethiopia", African Journal of Food Science, 4 (13), pp. 790-802, (2010).

4. Bala, B. K. and Debnath, N. "Solar Drying Technology: Potentials and Developments", Journal of Fundamentals of Renewable Energy and Applications, 2012, 2: doi:10.4303/jfrea/R120302. (2012).

5. Mustayen, A. G. M. B., Mekhilef, S. and Saidur, R. "Performance Study of Different Solar Dryers: A Review", Renewable and Sustainable Energy Reviews, 34 pp. 463-470, (2014).

6. Ringeisen, B., Diane, M. and Barrett, P. S. "Concentrated Solar Drying of Tomatoes", Energy for Sustainable Development, 19, pp. 47-55, (2014).

7. Okonkwo, W. I. and Okoye, E. C "Performance Evaluation of a Pebble Bed Solar Crop Dryer", Nigerian Journal of Technology (NIJOTECH), 24 (2), pp. 67-73, (2005).

8. Sadodin, S. and Kashani, T. T. "Numerical Investigation of a Solar Greenhouse Tunnel Dryer for Drying of Copra", arxiv.org/pdf/1102.4522, 2016, Accessed on June 9, (2016).

9. Kennedy, D. "5 A Day the Sun-Dried Way" Leaf for Life, (2002).

10. Mohsin, A. S. M., Maruf, M. N. I., Sayem, A. H. M., Mojumdar, M. R. R, and Farhad, H. M. S. "Prospect and Future of Solar Dryer: Perspective Bangladesh", IACSIT International Journal of Engineering and Technology, 3 (2), pp. 165-170, (2011).

11. Hubackova, A., Kucerova, I., Chrun, R., Chaloupkova, P. and Banout, J. "Development of Solar Drying Model for Selected Cambodian Fish Species", Hindawi Publishing Corporation, (2014), http://dx.doi.org/1 $\underline{0.1155 / 2014 / 439431}$

12. Adugna, W. D. and Berecha, G. "Determining Slice Thickness of Banana (musa spp.) for Enclosed Solar Drying Using Solar Cabinet Dryer under Ethiopian Condition", American Journal of Food Technology, Academic Journals Inc., 6 (7), pp. 568-580, (2011).

13. Hassanain, A. A. "Simple Solar Drying System for Banana Fruit", World Journal of Agricultural Sciences, 5 (4), pp. 446-455, (2009).
14. Aissa, W., El-Sallakb, M. and Elhakem, A. "Performance of Solar Dryer Chamber Used for Convective Drying of Sponge-Cotton", Thermal Science, 18 (2), pp. 451-462, (2014).

15. Onwuka, U. N. and Nwachukwu, G. "Grain Size and Heat Source Effect on the Drying Profile of Cocoa Beans", Nigerian Journal of Technology (NIJOTECH), 32 (3), pp. 417- 423, (2013).

16. Chappell, C. and Lebel, S. "Solar Drying Shed for Cassava in Malawi", Department of Bioresource Engineering, McGill University Quebec, Canada, (2008).

17. Lee, C., Chou, P., Chiang, C. and Lin, C. "Sun Tracking Systems: A Review”, Sensors, 9, pp. 3875-3890, (2009), doi:10.3390/s90503875. (2009).

18. Ghassoul, M. "Design of an Automatic Solar Tracking System to Maximize Energy Extraction", International Journal of Emerging Technology and Advanced Engineering, 3 (5), pp. 453-460, (2013).

19. Brandley, A. "Solar Tracking Application", Rockwell Automation, Inc., (2011).

20. Pirasteh, G., Saidur, R., Rahman, S. M. A. and Rahim, N. A. "A Review on Development of Solar Drying Applications", Renewable and Sustainable Energy Reviews, 31, pp. 133-148, (2014).

21. Alonge, A. F. and Hammed, R. O. "A Direct Passive Solar Dryer for Tropical Crops", African Crop Science Conference Proceedings, African Crop Science Society, 8, pp.1643-1646, (2007).

22. Hellevang, K. J. "Grain Moisture Content Effects and Management", North Dakota State University (NDSU), Fargo, NDSU Extension Service; (1995).

23. Venkatesan, N. and Arjunan, T. V. "An Experimental Investigation and Performance Analysis of a Solar Drying of Bitter Gourd Using an Evacuated-Tube Air Collector", International Journal of ChemTech Research CODEN, 6 (14), pp. 5510-18, (2014).

24. ASHRAE. "Thermal Properties of Foods-Refrigeration Application for Foods and Beverages", American Society of Heating, Refrigeration and AirConditioning Engineers Handbook-Refrigeration (SI), ASHRAE, pp. 9.1-9.32, (2006).

25. Kassem, A. S., Al-Sulaiman, M. A., Aboukarima, A. M. and Kassem, S. S. "Predicting Drying Efficiency During Solar Drying Process of Grapes Clusters in a Box Dryer Using Artificial Neural Network", Australian Journal of Basic and Applied Sciences, 5(6), pp. 230-241, (2011).

26. Ohijeagbon, I. O., Adekunle, A. S. and Awolaran, O. D. "Enhancement of Thermal Capabilities of a Solar Concentrator", New York Science Journal, 2 (2), pp. 61-68, (2009).

27. Rogers, G. F. C. and Mayhew, Y. R. Engineering Thermodynamics-Work and Heat Transfer, Longman Group Ltd., UK, (1992). 